\title{
Choice of Sustainable Development Path of Agriculture Based on Ecological Civilization
}

\author{
George Rubin \\ Emory University, Atlanta, USA.
}

How to cite this paper: George Rubin. (2021) Choice of Sustainable Development Path of Agriculture Based on Ecological Civilization. Advance in Sustainability, 1(1), 7-11.

DOI: 10.26855/as.2021.07.002

Received: June 4, 2021

Accepted: June 28, 2021

Published: July 14, 2021

"Corresponding author: George Rubin, Emory University, Atlanta, USA.

\begin{abstract}
The United States is one of the first developed countries in the world to practice ecological agriculture. Based on the perfect legal guarantee, sufficient financial support and strong scientific and technological strength, the United States has become a more successful country in the development of ecological agriculture in the world. This paper analyzes the sustainable development of ecological agriculture in the United States, discusses the importance of ecological civilization, clarifies the necessity of sustainable development of agriculture, analyzes various problems existing in it, and puts forward targeted opinions and suggestions, so as to promote sustainable development of agriculture based on ecological civilization.
\end{abstract}

\section{Keywords}

Ecological Civilization, Agriculture, Sustainable Development, The Path

\section{Introduction}

The United States is one of the first developed countries in the world to practice ecological agriculture and to develop ecological agriculture successfully at present. In the new era, both the government and all sectors of society pay great attention to the construction of ecological civilization, the harmonious coexistence between man and nature, and the balance between society and nature. In the process of developing agricultural development, we must not neglect the construction of ecological civilization, so as to reduce and avoid the contradiction between agricultural development and the environment. Ecological agriculture is a new type of comprehensive agricultural system which organically combines the achievements of modern science and technology with the essence of traditional agricultural technology and has the function of rational structure and benign circulation.

\section{Overview of ecological civilization}

Ecological civilization has a natural attribute. By applying it to agriculture, it can achieve the goal of building and protecting a better environment, and also promote the harmony between man and nature. In this kind of ecological civilization, we should give priority to ecology and harmony between man and nature. The law of agricultural development should be in line with the law of natural development, and agriculture should be developed without violating the law of nature, so as to promote the common development of agriculture and ecology. In a way, ecological civilization is also people's reflection on human society. The 21st century is a period of economic explosion and rapid economic growth, but it is accompanied by a variety of environmental pollution, people cannot bear a variety of "natural disasters" caused by their own behavior. In terms of agricultural development, there are some problems such as excessive reclamation, and some industries occupy good farmland in the process of development, reducing the area of arable land, which is not conducive to the development of agriculture. In addition, some factory construction site is not reasonable and sewage is not reasonable discharge, leading to sewage pollution of farmland, farmland quality deterioration, gradually abandoned. In the long run, farmland will be less and less, and agricultural develop- 
ment will be difficult. In this case, ecological civilization is very important. In the process of agricultural development, we should adhere to the concept of ecological civilization, pay attention to the harmonious coexistence between man and nature, and develop agriculture on the premise of not affecting the future development of agriculture, which is conducive to the sustainable development of agriculture.

\section{Main characteristics of modern agriculture under the background of ecological civilization}

\subsection{Construction of the agricultural form of production effect}

In the past, due to the limitation of various conditions, people mostly adopted extensive agricultural production methods. But in the change of times, intensive agriculture gradually came into being, and it is also the goal of agricultural transformation. From the perspective of intensive agriculture itself, it mainly concentrates a certain amount of labor and means of production in the process of agricultural production and applies them to a small land. Through the utilization of this form of operation mode, the quality and efficiency of obtaining agricultural and sideline products can be improved. Therefore, it is imperative to replace extensive agricultural production mode with intensive agricultural production mode, which is the trend of agricultural production and development, and more in line with the characteristics of agricultural production at the same time. The main characteristics of this development are as follows: increasing the supply of crop fertilizer, innovating irrigation technology, transforming medium and low yield fields by technology, attaching importance to mechanized production, selecting excellent varieties, etc.

\subsection{Resource-conserving agricultural methods with circular characteristics}

The resource-conserving energy mode with the characteristic of recycling is mainly based on the related technology of material recycling, and in the process of agricultural development, according to the specific situation of different agricultural resources, it will be promoted to the high efficiency and multi-level trend. In the agricultural production, every link is very important, each link is progressive transformation at the same time, a link is the foundation of another part, another part on the basis of the previous link, in this process, the entire system for effective recycling of waste, can greatly improve the efficiency of agricultural production, increase the rate of resource use, come in and reduce the emission of waste gas resources to achieve agricultural products.

\subsection{Establishing a green agricultural system that makes agricultural products safe}

In green agriculture, we need to pay attention to the whole process of agricultural production, not only need to pay attention to environmental protection, but also need to pay attention to the safety of crop quality and other aspects of the problem, which is closely related to our daily production of organic food. In order to better produce this green agriculture, it is necessary to increase the use of modern culture of new agricultural technology, but also need to be based on the specific situation of the production of products, a good production and sales model, to ensure each process of agricultural production, to ensure the quality of agricultural products.

\section{Sustainable agricultural development path based on ecological civilization}

\subsection{Improve scientific and technological strength}

The United States has a sound system of ecological agricultural research and application. In 1988, LISA was put forward, and in 1990, HESA was put forward. It was the first to explore an agricultural production system with environmental protection as the main target and relying on scientific and technological progress, and it was tried out in more than 30,000 farms in the Northeast, North Central, South and West of the United States. In the late 1990s, the Kansas Land Research Institute experimented with growing perennial wheat and corn without having to plant it every year. Then carried out rotation of crop rotation, the leisure, crop residues cover less zero tillage, crop integrated pest management, conservation tillage, agricultural renewable resources use (coverings, manure), gm varieties development, network technology and a series of technical experiments and research, a large number of agricultural scientists to participate in the activities of the experimental study on the ecological agriculture technology; 1990 years later, the agricultural experiment research department has developed out of the use of precision agriculture machinery of $3 \mathrm{~s}$ technology, it is equipped with computer control system, production control detector, laser measuring technology and other advanced technology and equipment, and precision agriculture technology tests have been carried out on the farm in Minnesota, using GPS guiding fertilization of crop output is about 30\% higher than traditional balanced fertilization crop yields. After the success of the experiment, the production management of wheat, corn, soybean and other crops began to apply precision agriculture technology. Precision agriculture grew rapidly in the United States in the mid-1990s, with the number of harvesters equipped with yield monitors growing to 35,000 by 2009. A U.S. Agricultural 
Research Service (USARS) national research project on the competitiveness and sustainability of agricultural systems (involving 15 states) represents the latest direction in the research of ecological farming systems in the developed world. Due to the high degree of agricultural informatization in the United States, rapid progress has been made in the fields of ecological agricultural technology extension and agricultural testing.

\subsection{Establish a "Five-in-One” linkage in agriculture to promote sustainable agricultural development}

Since the late 1980s, in order to promote the implementation of the strategy of agricultural sustainable development, the United States has successively carried out two important plans. The common feature of these two programs is that the government's agricultural policies and regulations, financial support, agricultural science and technology research and promotion and agricultural education are organically integrated, and the "five-in-one" linkage is carried out to promote the sustainable development of agriculture. One is to buy a low-input plan for sex resources. In the late 1980s, the United States government implemented the sustainable agricultural development program with low input of purchasing resources. The main direction of the program was to establish an agricultural production system favorable to the protection of the ecological environment, and through legislation, the government allocated special funds to carry out the program. The second is the continuing agricultural research and education program. Since 1990, the U.S. government in the implementation of purchasing resources, on the basis of low input plan, in order to more accurately reflect the essence of the strategy of agricultural sustainable development, it was renamed "sustainable agriculture research and education program", in order to emphasize the sustainable agriculture is not simply advocate low input, but to decrease the material through the high input of intelligence, replace material capital investment with human capital investment. The main features of the implementation of this plan are:

Establish a national sustainable agriculture research network. At the federal level and the ecological agriculture, sustainable agricultural research respectively by the different social background, can widely nationally commission on behalf of the interests of all parties and the regional sustainable agriculture research education steering committee, involving national and an important research topic in agricultural zone and the corresponding funds to make decisions. At the regional level, the steering committee is usually attached to a state university by taking advantage of the advantages of each state university. Focus on information service. Information services for sustainable agriculture are considered to be one of the keys to success. The United States Department of Agriculture (USDA) has set up the "Information Center for Alternative Agriculture Systems" in the USDA Library to collect research papers, reports and monographs on sustainable agriculture from around the world, and compile and publish the CD-ROM index for the use of research extension workers.

\subsection{Improve agricultural information technology}

In the early 1980s, due to the decrease of corn and other crops caused by organic agriculture, the United States put forward a new farming system of "sustainable agriculture" on the basis of organic agriculture and ecological agriculture. Sustainable agriculture emphasizes that agriculture is ecologically self-sustaining, multistage recycling, and economically efficient. It requires the rural soil, water, seed, fertilizer, medicine, electricity, grain and other production factors to carry out overall planning and systematic development, follow the principle of "reduction, reuse, recycling", in order to produce significant economic benefits and increase farmers' income. Argo-grazing is a common feature of most large farms in the United States. The farm pays attention to the mutual promotion and coordination between the breeding industry and the planting industry in the aspects of feed and fertilizer. Farming animal manure or through the pipeline or direct dry solidification into organic fertilizer returned to the farmland, not only to prevent environmental pollution, and improve the fertility of the soil. It has been the dominant technology in no-till farmland in the United States for 20 years. It mainly uses mechanized crushing of wheat, soybean, peanut and other crop stalks to return to the field and high retention harvesting to return directly to the field, and uses special 6-row or 4-row large and medium-sized no-tillage sowing. Numerous experiments have shown that this method can significantly reduce the amount of fertilizer used, increase soil organic matter, retain moisture, and control weeds. Today, about 70 percent of farmland in the United States uses this technology.

\subsection{Saving and full utilization of resources}

In the process of sustainable agricultural development based on ecological civilization, resources are very important, including both water resources and cultivated land resources. The situation is different for each resource. Water tends to be in shortage, as is arable land. As the most important resources in agriculture, in the process of carrying out agricultural activities with these resources, it is necessary to take measures to protect or save them according to the specific situation of the resources, so as to realize the sustainable development of ecological civilization agriculture. In the process of using water resources, water resources should be saved as much as possible. In the process of using cultivated land, it is necessary to protect cultivated land resources, which will be discussed in the following paragraphs.

Large-scale industrial agriculture in the United States is a global model, but in recent years, there has been a growing recog- 
nition of its shortcomings. It is in this context that the "small-scale, intensive and diversified" ecological farms have ushered in their spring. The American ecological farm, born in this way, naturally puts "ecology" at the height of the core value. These days, "circular agriculture" is a basic part of any eco-farm. No fertilizers, no pesticides, no hormone-added feed that goes without saying. Their "ecological" concept is more reflected in a sustainable development model. For example, crops are fed to animals, and animal waste is broken down by microbes and made into organic fertilizer to help crops grow. For example, according to different crop cultivation period, put chickens, ducks and geese to eat weeds and pests. This "circular agriculture" mode, through the multi-stage utilization of energy and material recycling, to achieve the ecological balance of farm organisms themselves. Eco-farms are more productive than industrial agriculture, which destroys the soil, and have no environmental impact on the surrounding community.

\subsection{Perfect legal system}

The development of ecological agriculture in the United States has a complete set of laws and regulations as a guarantee. As early as 1990, the Pollution Prevention Act of the United States promulgated clear provisions on ecological agriculture. The 1990 Agriculture Act of the United States passed by the Congress selected research and education approaches in the form of legislation to establish a sustainable, profitable and resource-protecting agricultural production system. In order to implement the low-input development model, the government has formulated standards for the quantity of pesticides and fertilizers in the form of laws and regulations, which stipulate those taxes on pesticides and chemical fertilizers should be levied in the form of investment taxes on those who produce and use pesticides and fertilizers that cause environmental pollution. General agricultural production in the United States must comply with seven laws and regulations, namely, the Seed Act and the Species Conservation Act, the Fertilizer Use Act, the Natural Resources Conservation Act, the Land Resources Conservation Act, the Plant Protection Act, the Garbage Dispose Act, and the Water Resources Management Act. In order to ensure the quality of ecological agricultural products, on the basis of relevant laws and regulations, the United States has also developed supporting agricultural product quality and safety certification standards. It stipulates that organic crop must stop using banned substances for three years before being certified, that they must comply with the Organic Plan when performing organic cultivation, that farmers applying for a license must submit an organic crop production plan to the certification body, and that farmers must keep records of all growing processes for five years.

\subsection{Support for production}

Currently, there are more than 20,000 ecological farms in the United States, and these ecological farms have become the main object of financial support for ecological agriculture in the United States. Since the 1990s, the United States started the pilot of agricultural subsidies "green", set up some mandatory conditions, require the subsidies to farmers must check their environmental behavior, regular surveys its farm area of wild resources, forest, vegetation, test of soil, water, air, and carried out according to the environmental protection of farmers' quality, the government decided to whether subsidies and subsidies, In addition to providing "green subsidies" to outstanding farmers, agricultural income tax will be temporarily reduced or exempted. In the process of ecological agriculture system reform, in order to guide the farm to adopt a leisure way to reduce production cost and conserve water and soil, the American government formulated a seed subsidy policy. The $24 \%$ of the arable land prone to soil loss in the United States was fallow for 10 to 15 years, and farmers who returned fallow land to forest or grass received government subsidies. In view of the development requirements of ecological agriculture, the United States has significantly increased the investment in agricultural ecological environmental protection in recent years.

\section{Summary}

In the economic and social development, agricultural production is very important, it is the basis of the development of various industries. Therefore, it is necessary to pay more attention to agricultural production and realize the sustainable development of agricultural production. However, in today's era, various kinds of pollution and damage are becoming increasingly serious, so that there are certain problems in agricultural production, such as the contradiction between supply and demand of agricultural products, environmental pollution, etc., which may lead to its inability to achieve sustainable development. In view of this situation, it is necessary to pay attention to the construction of agriculture based on ecological civilization. Ecological civilization is important, it is the foundation of agricultural construction, plays an important role in the sustainable development of agriculture, but also conducive to the realization of sustainable development of agriculture. This paper discusses various problems existing in the process of agricultural production, and puts forward relevant measures to help the sustainable development of agricultural construction based on ecological civilization, so as to leave a better ecological environment for our future generations, so that they can build a better life. 


\section{References}

[1] Parr, J. F., Papendick, R. I., Youngberg, I. G., et al. (2020). Sustainable agriculture in the United States [M]//Sustainable agricultural systems. CRC Press, 2020: 50-67.

[2] Foguesatto, C. R., Borges, J. A. R., Machado, J. A. D. (2020). A review and some reflections on farmers' adoption of sustainable agricultural practices worldwide [J]. Science of the Total Environment, 2020, 729: 138831.

[3] Mottet, A., Bicksler, A., Lucantoni, D., et al. (2020). Assessing transitions to sustainable agricultural and food systems: A Tool for Agroecology Performance Evaluation (TAPE) [J]. Frontiers in Sustainable Food Systems, 2020, 4: 252.

[4] Inass, Z., Karima, B., Mohammed, A., et al. (2019). Agroforestry: Smart Practice for Sustainable Agricultural Development [C]//International Conference on Advanced Intelligent Systems for Sustainable Development. Springer, Cham, 2019: 36-47.

[5] Liu Yu hang, Zhang Hong Chen, Wang Zahedan, et al. (2015). A study on the development of agricultural production efficiency in China: A case study of the United States, Japan and Australia [J]. World Agriculture, 2015, (2): 60-63. 